\title{
Social epistemological conception of delusion
}

\author{
Kengo Miyazono ${ }^{1}\left[\right.$ (1) Alessandro Salice ${ }^{2,3}$ (1) \\ Received: 1 November 2019 / Accepted: 4 September 2020 / Published online: 17 September 2020 \\ (C) The Author(s) 2020, corrected publication 2021
}

\begin{abstract}
The dominant conception of delusion in psychiatry (in textbooks, research papers, diagnostic manuals, etc.) is predominantly epistemic. Delusions are almost always characterized in terms of their epistemic defects, i.e., defects with respect to evidence, reasoning, judgment, etc. However, there is an individualistic bias in the epistemic conception; the alleged epistemic defects and abnormalities in delusions relate to individualistic epistemic processes rather than social epistemic processes. We endorse the social epistemological turn in recent philosophical epistemology, and claim that a corresponding turn is needed in the study of delusions. It is a turn from the (purely) individualistic conception, which characterizes delusions only by individualistic epistemic defects and abnormalities, to the (partially) social epistemic conception, which characterizes delusions by individualistic as well as social epistemic defects and abnormalities. This paper is intended as an initial step toward such a social epistemological turn. In particular, we will develop a new model of the development of delusions according to which testimonial abnormalities, including testimonial isolation and testimonial discount, are a causal factor in the development of delusions.
\end{abstract}

Keywords Delusion · Schizophrenia · Testimony · Social epistemology · Group identification

Kengo Miyazono

miyazono@let.hokudai.ac.jp

Alessandro Salice

alessandro.salice@ucc.ie

1 Department of Philosophy and Religious Studies, Hokkaido University, Kita 10, Nishi 7 ,

Kita-ku, Sapporo, Hokkaido, Japan

2 Department of Philosophy, University College Cork, 4 Elderwood, College Road, Cork, Ireland

3 Center for Subjectivity Research, University of Copenhagen, Copenhagen, Denmark 


\section{Introduction}

The dominant conception of delusion in psychiatry (in textbooks, research papers, diagnostic manuals, etc.) is predominantly epistemic (Bortolotti 2013; Broome and Bortolotti 2009). Delusions are almost always characterized in terms of some epistemic notion, e.g., evidence, reasoning, judgment, etc. For instance, the Diagnostic and Statistical Manual of Mental Disorders 5th Edition (DSM-5) characterizes delusions as "fixed beliefs that are not amenable to change in light of conflicting evidence" (American Psychiatric Association 2013, p. 87), and they are said to be "based on incorrect inference about external reality" and "firmly held despite what almost everyone else believes and despite what constitutes incontrovertible and obvious proof or evidence to the contrary" (American Psychiatric Association 2013, p. 819).

Looking closer, however, we can find a bias in the epistemic conception of delusions in psychiatry; this is an individualistic bias. The epistemic conception tends to characterize delusion in terms of what we call "individualistic sources of evidence" rather than "social sources of evidence." Individualistic sources of evidence (e.g., perception, reasoning, memory) are those that an epistemic agent can have without interaction with other epistemic agents. Social sources of evidence (e.g., testimony), by contrast, are those that an epistemic agent can have only with interaction with other epistemic agents. The individualistic bias can be seen in DSM-5, which characterizes delusions in terms of a failure of inference (which is an individualistic source of evidence), not in terms of a failure of testimony (which is a social source of evidence). ${ }^{1}$

The same bias, i.e., the individualistic bias, had been pervasive in philosophical epistemology until recently; the bias consists in thinking of an epistemic agent as "a single individual who undertakes the task [of seeking truth] all by himself/herself, without consulting others" (Goldman and O'Connor 2019). Against this bias, social epistemologists defend an alternative conception of the epistemic agent as someone who "pursue[s] the truth [...] with the help of, or in the face of, others" (Goldman and O'Connor 2019), and they discuss epistemological issues concerning such an epistemic agent, such as testimony, peer disagreement, etc.

\footnotetext{
1 Some might reject the contrast between testimony, which is social, and inference, which is individualistic, possibly on the basis of a Humean reductionist idea according to which testimony eventually reduces to (inductive) inference. We have two comments in response to this objection. First, the reductionism/antireductionism debate in the epistemology of testimony is not directly relevant to our project. It is an epistemological debate concerning justification by testimony. By contrast, our focus in this paper is not on justification by testimony, but on the psychological process of testimony. Second, we do not rule out the possibility that the psychological process of testimony involves some form of inference (which is in fact quite reasonable given a broad notion of "inference"). Still, testimony is inherently social in the sense that it presupposes interactions with others. Inference (in non-testimonial cases), by contrast, is not inherently social in this sense.
} 
We endorse this social epistemological turn in philosophical epistemology ${ }^{2}$ and claim that a corresponding turn is needed in the study of delusions. It is a turn from the (purely) individualistic study of delusion in which only individualistic sources of evidence (e.g., perception, reasoning) are investigated (e.g., whether delusional patients reasonably respond to perceptual evidence or not, whether delusional patients reason correctly or not, etc.) to the (partially ${ }^{3}$ ) social study of delusion in which social sources of evidence (e.g., testimony) are also investigated (whether delusional patients reasonably respond to testimonial evidence or not, etc.)

This paper is intended as an initial step toward such a social epistemological turn in the study of delusions. As an initial step, this paper aims to develop a new model of the etiology of delusions according to which testimonial abnormalities are a causal factor in the development of delusions.

Our approach is motivated by two general ideas. The first idea, which is at the core of social epistemology, is that much (or perhaps most) of what we believe and know is based on social sources of evidence. As Goldman notes, "what people believe and know is largely a function of their community and culture, narrowly or broadly construed. Most of what we believe is influenced, directly or indirectly, by utterances and writings of others" (Goldman 1999b, p. 3).

The second idea concerns the social abnormalities in schizophrenia, which have been noted by clinicians and researchers. Here is a classic observation of the asocial nature of schizophrenia made by Jaspers:

It is to a certain extent characteristic for the large group of those who are mentally ill in the narrower sense and whom we nowadays class together as schizophrenic that they should exclude themselves from human society in some form or another. They erect a new world inside themselves in which they predominantly live even though to the superficial observer they may seem to be quite in touch with the real world. They have no urge to share this realm of feelings, experiences and delusional ideas which is solely their own. [...] The individuals who-in typical cases-shut themselves off from others without seeming to notice it or suffering in any way from it have always formed a group of socially dead people. (Jaspers 1963, pp. 724-725).

Merging these ideas sustains the reasonable expectation that belief formation and knowledge acquisition are disturbed in schizophrenia in one way or another because of the social abnormalities in this condition. Our claim is that this disturbance is part of the etiology of delusions in schizophrenia. ${ }^{4}$

\footnotetext{
${ }^{2}$ Here we assume a rather narrow conception of social epistemology, the one that discusses epistemological issues concerning individual doxastic agents with social evidence (the "first variety" of social epistemology, according to Goldman 2011). Social epistemology, broadly construed, also discusses epistemological issues concerning collective doxastic agents (the "second variety") and epistemic systems (the "third variety"). The collective variety and the systemic variety of social epistemology can also have interesting implications for the study of delusions, but we will not discuss these ideas in this paper. For a related discussion of shared delusions, see Sect. 4.

3 We speak of the partially rather than purely social epistemic conception, because it does not rule out the relevance of individualistic defects and abnormalities.

4 For further discussion of social factors in the development of delusions, see the papers by Freeman and colleagues, including Freeman et al. (2001, 2002). See also Cameron (1959) and Fuchs (2015). For a
} 
It is worth noting that our model does not aim to replace existing theories of delusions. First, our claim is that testimonial abnormalities are a causal factor in delusions in schizophrenia. Thus, it is compatible with other theories, such as the two-factor theory (see Sect. 2), that are primarily about non-schizophrenic delusions. Second, our claim is that testimonial abnormalities are $a$ causal factor, rather than the causal factor, in delusions in schizophrenia. Thus, it is compatible with other theories; e.g., our model captures one aspect of the etiology of delusions, and other theories capture other aspects. See Sect. 3.1 for more details.

We begin with an overview of the existing theories of the etiology of delusions (Sect. 2). We observe that existing theories are mostly individualistic; they explain delusions in terms of abnormal experiences and/or abnormal reasoning of deluded individuals. Then, we propose our model, which explains how testimonial abnormalities can causally contribute to different stages of the development of delusions (Sect. 3). Finally, we consider potential objections to our model (Sect. 4).

\section{Previous models of delusions}

A delusion is, roughly, a belief that is held despite obvious counterevidence and that is not explained by the person's social, cultural or religious background. ${ }^{5}$ Delusions feature in an array of psychiatric and neurological conditions including schizophrenia, dementia, and acquired brain injury. Delusions are typically (but not necessarily) false, and their content can be (but does not have to be) bizarre. Delusions are classified into sub-categories according to theme or topic. The delusion of persecution, for example, involves the idea of being harmed or harassed by an individual or group. The Capgras delusion involves the idea that a familiar individual has been replaced by an imposter.

In many cases, delusions occur in one of two ways (Davies et al. 2001). First, the delusions of patients can be circumscribed (i.e., the delusions are rather isolated in their system of beliefs) and monothematic (i.e., the delusions focus on a particular topic; their beliefs are quite normal concerning other topics). Second, the delusions of patients can be elaborated (i.e., the delusions form an intricate delusional system of beliefs) and polythematic (i.e., the delusions involve multiple topics). Roughly, delusions in schizophrenia tend to be elaborated and polythematic, while delusions due to neuropsychological deficits tend to be circumscribed and monothematic (Davies et al. 2001; Stone and Young 1997). ${ }^{6}$ Our main focus in this paper is the former

\footnotetext{
Footnote 4 continued

philosophical discussion of testimony in delusions and religious beliefs, see Radden (2010) and Murphy (2013).

5 There is, however, an ongoing philosophical debate as to whether or not delusions are really beliefs (Bortolotti 2010). For the purposes of this paper, we operate under the assumption that delusions are beliefs. Note, however, that we do not rule out the possibility that delusions typically involve something more than abnormal beliefs (e.g., feelings, moods, etc.) or that some delusions are so different from what we ordinarily call "beliefs" that they might be excluded from the psychological category of belief.

6 Here we assume that elaboration and polythematicity co-occur and that circumscription and monothematicity co-occur. As Davies and colleagues point out, however, this assumption might not be perfectly accurate: "it is worth noting that monothematicity and circumscription are, strictly speaking, independent of each other" (Davies el al. 2001, p. 135). For example, it is possible that some monothematic delusions become elaborated to some extent.
} 
group of delusions. As we will see, our model of the etiology of delusions is particularly promising when it comes to explaining elaborated and polythematic delusions in schizophrenia.

Why do delusional patients believe what they believe? Where do the delusions come from? What causes delusional beliefs? In answering these questions, a number of theories regarding the etiology of delusions have been proposed. Here is an overview of some of the leading ones. (But note that this overview does not cover all theories.)

1. Reasoning Abnormality Accounts Some theorists argue that delusions are (mainly) caused by some reasoning abnormalities. Von Domarus (1944) presents a classic reasoning abnormality account according to which delusions arise from abnormal failures of syllogistic reasoning. Von Domarus' view is not widely accepted, mainly because of the lack of supporting evidence concerning syllogistic reasoning abnormalities. However, researchers found other reasoning-related abnormalities. One of the most famous findings concerns the jumping-to-conclusions bias (Garety and Hemsley 1997; Huq et al. 1988), which is the bias of coming to a conclusion more quickly than non-clinical subjects. Another finding concerns the bias against disconfirmatory evidence (Moritz and Woodward 2006; Woodward et al. 2006), which is the bias of failing to incorporate evidence contrary to one's prior belief.

2. Experiential Abnormality Accounts Other theorists claim that delusions are (mainly) caused by some experiential abnormalities (Maher 1974; Kapur 2003). A notable experiential abnormality account is the one by Maher (1974), who denies the relevance of reasoning abnormalities and argues that delusions are caused by abnormal perceptual experiences. According to Maher, delusions arise when patients try to explain their abnormal perceptual experiences. Their perceptual experiences are abnormal, whereas their explanation of them is normal and reasonable: "the explanations (i.e., the delusions) of the patient are derived by cognitive activity that is essentially indistinguishable from that employed by non-patients, by scientists, and by people generally" (Maher 1974, p. 103).

3. Multifactorial Accounts The third group of theorists proposes multifactorial accounts that combine two or more causal factors. For example, Stone and Young (1997) appeal to both experiential and reasoning factors in explaining the Capgras delusion, i.e., an abnormal perceptual-affective experience of a familiar face and a reasoning bias called the "bias towards observational adequacy," which is the bias of placing more emphasis on incorporating new observations into the belief system at the expense of its stability. The most influential multifactorial account is the "two-factor theory" by Coltheart and colleagues (Coltheart 2007; Coltheart et al. 2011). According to their theory (in its 2010 version; Coltheart et al. 2010), there are two dissociable causal factors in the development of delusions. In the case of the Capgras delusion, for example, the first factor has something to do with abnormal autonomic responses to familiar faces, and the second factor is an abnormal neglect or discount of evidence against the Capgras hypothesis.

4. Prediction Error Accounts The fourth group of theorists, prediction error theorists, argues that delusions are the product of faulty processing of prediction errors (Corlett et al. 2010; Fletcher \& Frith 2009), which is consistent with a number of empirical studies, including the one by Corlett et al. (2007). Prediction error 
theorists deny the fundamental assumption in the debate between experiential and reasoning abnormality accounts, namely, that experiential and reasoning abnormalities can be clearly distinguished from one another. According to prediction error accounts, both experiential and reasoning factors are subsumed under one single factor, namely, the disrupted processing of prediction errors: "[a]n important principle that has emerged is that both perception of the world and learning about the world (and therefore beliefs) are dependent on predictions and the extent to which they are fulfilled. This suggests that a single deficit could explain abnormal perceptions and beliefs" (Fletcher and Frith 2009, p. 51).

The above summary makes it clear that mainstream theories of the etiology of delusions tend to focus on individualistic factors, such as (abnormal) experiences or (abnormal) reasoning. ${ }^{7}$

It is very likely that the mainstream theories, or at least some of them, capture important aspects of the development of delusions. However, mainstream theories might not tell the whole story. They might not explain all the crucial facts about the etiology of delusions. Among others, we will mention two remaining issues that are particularly important for our discussion.

The first issue is that mainstream theories might not explain why delusions-especially those in schizophrenia-can be elaborated and polythematic. Let us consider the following case of elaborated and polythematic delusions in schizophrenia.

A Thirty-Three-Year-Old Man with Chronic Schizophrenia. The patient had been ill for fourteen years. At the time of the interview, he was preoccupied and distressed by the firm belief that he had no internal organs. Although his doctors had told him that this was a physiological impossibility, and despite some acknowledgement on the part of the patient that he could not quite understand how such a thing was possible, the patient said that he could not rid himself of the belief. The patient also expressed the belief that spirit doctors had come to his room one night to perform a magical operation in order to remove his internal organs. This happened, he believed, because he was being punished by God for some evil or sin that he had committed, although he was uncertain about the nature of that sin. The most distressing aspect of the delusion for this patient was the pervasive worry that, when he died, he would be rejected from heaven because he was no longer a proper human being (Davies et al. 2001, p. 136).

Experiential abnormality theorists such as Maher would argue the patient experiences some abnormal somatic feelings, which is why he comes to believe that he has no internal organs. Coltheart et al. (2010) would argue that the patient neglects or discounts evidence, which is why he cannot revise his belief despite the doctor's telling him that it is physiologically impossible that he has no internal organs. But, there is little discussion in mainstream theories of why his delusions are elaborated and polythematic, of why the patient believes not only that he has no internal organs, but also that spirit doctors removed his internal organs, that he was punished by God for some evil or sin, that he will be rejected from heaven, and so on.

\footnotetext{
${ }^{7}$ See, however, Freeman et al. $(2001,2002)$, for example.
} 
An exception is the paper by Coltheart and colleagues (2011; see also Coltheart 2013) in which, from a two-factor theoretic point of view, they suggest three ideas about how delusions can be elaborated; delusions become polythematic when (1) multiple first factors are present, (2) the second factor is particularly severe, and (3) the first factor is ambiguous and open to multiple interpretations. But they admit that these are "speculative answers" (Coltheart et al. 2011, p. 293) that, at this moment, have not been supported by empirical evidence.

The second issue is that mainstream theories might not explain why delusional patients seem to be responsive to some forms of evidence, but not to others. It is very likely that the schizophrenic patient in the case above adopts the delusional hypothesis that he has no internal organs in response to abnormal somatic feelings. This means that, on the one hand, the patient is responsive to evidence in the form of abnormal experience. On the other, the patient is not responsive to evidence when the doctor tells him that it is physiologically impossible that he has no internal organs. In fact, not being responsive to conflicting evidence is widely regarded as one of the distinctive features of delusions in general. For example, we already noted that DSM-5 characterizes delusions as "fixed beliefs that are not amenable to change in light of conflicting evidence" (American Psychiatric Association 2013, p. 87).

But then there is a prima facie puzzle here; the schizophrenic patient is responsive to some forms of evidence (e.g., abnormal somatic feelings) but not to others (e.g., the doctor's telling him that it is impossible that he has no internal organs).

It should be emphasized that this is not a confirmation bias. It is not the case that the patient is responsive to abnormal somatic feelings (but not to the doctor's suggestion) simply because of his bias to favor the information that is consistent with his prior belief, i.e., his belief that he has no internal organs. After all, when he first experiences the abnormal somatic feelings, he does not have a prior delusional belief that he has no internal organs. Instead, his prior beliefs at that stage overwhelmingly support the idea that he does have internal organs. Thus, the confirmation bias hypothesis cannot explain why, despite his prior belief that he has internal organs, he responds to abnormal somatic feelings and reaches the delusional conclusion that he has no internal organs.

These two problems above, the problem of elaborated/polythematic delusions and the problem of evidence responsiveness, are not meant to be the devastating objections to mainstream theories. There will be some possible solutions. Our solution is to appeal to another theory, which we will propose in the next section, that supplements mainstream theories.

\section{Social factors in the development of delusions}

\subsection{The testimonial theory of delusions}

In this section, we introduce a new non-individualistic model of the etiology of delusions. Our model provides us with a detailed account of exactly how social abnormalities in schizophrenia causally contribute to some stages of the development of delusions. In its basic form, the model-we call it the "testimonial theory of delu- 
sions"-says that delusions in schizophrenia are partially explained by testimonial abnormalities, including (1) the loss of testimonial interaction with others (we call this "testimonial isolation") and (2) the discounting of testimonial evidence ("testimonial discount"). Both testimonial isolation and testimonial discount are general tendencies in schizophrenia, ${ }^{8}$ caused by social abnormalities characterizing the disorder (see Sect. 3.2 for details).

According to our model, testimonial abnormalities causally contribute to some stages of the development of delusions. Which stages, exactly?

We distinguish three different stages in the development of delusions. The adoption stage is the initial stage where the patient adopts a delusional hypothesis (e.g., "I have no internal organs") rather than an alternative, non-delusional hypothesis (e.g., "Perhaps my internal organs are not very healthy"). The maintenance stage is the next stage where, despite obvious counterevidence (e.g., the doctor's telling the patient that it is physiologically impossible that he has no internal organs), the patient maintains the delusional hypothesis. The elaboration/polythematization stage is an optional stage ("optional" in the sense that not all delusions go through this stage), where delusional hypotheses are elaborated and polythematized, forming an intricate delusional system of beliefs (e.g., the patient comes to believe not only that he has no internal organs, but also that spirit doctors removed his internal organs, that he was punished by God for some evil or sin, that he will be rejected from heaven, and so on).

Corresponding to the three stages of development of delusions, we can think of three possibilities for how testimonial abnormalities enter into the etiology of delusions:

The Adoption Stage Testimonial abnormalities can causally contribute to the adoption stage. For example, a patient has some abnormal somatic feelings and considers why he has them. Partly because of testimonial abnormalities, he adopts the implausible and delusional hypothesis that he has no internal organs. If he had not suffered from testimonial abnormalities, he would not have adopted the delusional hypothesis in response to the abnormal somatic feelings.

The Maintenance Stage Testimonial abnormalities can causally contribute to the maintenance stage. For example, after the delusional hypothesis is adopted, conflicting evidence becomes available to the patient, such as the doctor's telling him that it is physiologically impossible that he has no internal organs. Partly because of testimonial abnormalities, he fails to revise the delusional hypothesis in light of the conflicting evidence. If he had not suffered from testimonial abnormalities, he would have revised the delusional hypothesis that he has no internal organs.

\footnotetext{
8 A possible objection to this idea would be that, if testimonial isolation and testimonial discount are general tendencies, then they are psychological dispositions of individual epistemic agents. Accordingly, our account eventually amounts to an individualistic account of delusions in which some individualistic psychological dispositions are the fundamental causes of delusions. We counter the objection by highlighting that this possibility is compatible with our claim. After all, we haven't argued that testimonial isolation and testimonial discount are the fundamental causes (whatever that may mean exactly); we only claim that those epistemic deficiencies are causally relevant or that they are among the causal factors of delusions (in line with the multifactorial approach).
} 
The Elaboration/Polythematization Stage Testimonial abnormalities can causally contribute to the elaboration/polythematization stage. For example, the patient considers the implications of his delusional belief. He considers why he has no internal organs. Partly because of testimonial abnormalities, he reaches another implausible and delusional idea that he has no internal organs because he was punished by God for some evil or sin. If he had not suffered from testimonial abnormalities, he would not have endorsed this delusional idea.

These possibilities are not mutually exclusive. For example, testimonial abnormalities might be responsible for all the stages, at least in principle.

Several clarificatory remarks are in order.

First, we are pluralists about the etiology of delusions in the sense that we do not necessarily assume that all delusions are developed in the same way. Perhaps the testimonial theory is applicable to some delusions, but not to others. The testimonial theory is intended primarily as an account of delusions in schizophrenia; its applicability to delusions due to neuropsychological deficits is an open question.

Since our main target is delusions in schizophrenia, we remain open as to whether our theory can explain non-schizophrenic delusions. We do not consider this to be a problem for our proposal. For one thing, existing theories of the etiology of delusion also have limited scopes. The prediction-error theory is primarily about delusions in schizophrenia, and its applicability to non-schizophrenic delusions is still unclear. The two-factor theory is primarily about monothematic delusions (due to neuropsychological deficits), and its applicability to polythematic delusions (due to schizophrenia) is still unclear (for more discussions of the prediction-error theory and the two-factor theory, see Miyazono and McKay 2019). Moreover, because delusions in schizophrenia and those in neuropsychological deficits exhibit different features, the successful account of the former should be (at least partially) different from that of the latter. In particular, the successful account of delusions in schizophrenia needs to explain why they tend to be elaborated and polythematic, while the successful account of delusions due to neuropsychological deficits needs to explain why they tend to be circumscribed and monothematic.

Second, we are committed to the multifactorial approach, according to which the development of delusions is a complicated process in which different factors are involved. The testimonial theory does not say that testimonial abnormalities are the only factor in the development of delusions. Other (individualistic) factors, such as experiential or reasoning abnormalities, are not ruled out. For the same reason, the testimonial theory does not imply that testimonial abnormalities are sufficient for a person to develop delusional beliefs, or that any people with testimonial abnormalities develop some delusional beliefs.

Although testimonial abnormalities can causally contribute to all stages of the development of delusions in principle, we are inclined to think that they are not the main factor in the adoption stage. In many delusions, the main factor would be some abnormal experiential input (such as abnormal somatic feelings). The role, if any, of testimonial abnormalities is minimal or supplementary in the adoption stage. So, our view is that testimonial abnormalities are particularly relevant in accounting for the maintenance stage and the elaboration/polythematization stage. 
Since it is pluralistic and multifactorial, the testimonial theory does not compete with existing theories of the etiology of delusions, such as multifactorial accounts or prediction error accounts. Rather, the testimonial theory can supplement mainstream theories ${ }^{9}$ by addressing the remaining issues we saw in the last section, i.e., the problem of elaborated/polythematic delusions and the problem of evidence responsiveness.

First, the testimonial theory answers the question of why delusions can be elaborated and polythematic. A crucial part of the testimonial theory is the idea that testimonial abnormalities causally contribute to the elaboration/polythematization stage. We can explain not only why delusions can be elaborated and polythematic, but also why delusions in schizophrenia tend to be so. It is part and parcel of our hypothesis that testimonial abnormalities are typically associated with schizophrenia, caused by some deficits that can be seen in schizophrenia, which we will discuss in Sect. 3.2 (although we do not necessarily rule out the possibility that testimonial abnormalities are also present in other non-schizophrenic conditions). Thus, the fact that delusions in schizophrenia tend to be elaborated and polythematic can be explained by our proposal that testimonial abnormalities, which are typically associated with schizophrenia, causally contribute to the elaboration/polythematization stage.

Second, the testimonial theory explains why delusional patients seem to be responsive to some forms of evidence, but not to others. For example, the schizophrenic patient in our previous vignette is responsive to an abnormal somatic experience (which is why he adopted the delusional hypothesis that he has no internal organs), but not to the doctor's telling him that it is physiologically impossible that he has no internal organs (which is why he maintained the delusional hypothesis). We can explain this rather puzzling pattern if we assume that the patient responds to different kinds of evidence in different ways. In particular, the patient is especially irresponsive to testimonial evidence (such as the doctor's testimony) because of testimonial discount, but he does not have a corresponding problem with respect to experiential evidence (such as abnormal somatic feelings).

(Note, however, that it is not our view that delusional patients are irresponsive to testimonial evidence alone. They are probably irresponsive to non-testimonial evidence too. Even so, such irresponsiveness might also have something to do with testimonial abnormalities. See Sect. 3.2 for a discussion of how testimonial abnormalities can cause a patient to neglect or discount non-testimonial evidence.)

\subsection{Testimonial isolation and testimonial discount}

The remainder of Sect. 3 aims to make our model as credible as possible by filling in the details of the testimonial theory as well as reviewing the relevant evidence supporting it.

Let us begin with testimonial isolation, which involves a lack of testimonial interaction with others.

\footnotetext{
9 This corresponds to the idea in epistemology that social epistemology does not compete with but rather supplements individualistic epistemology. Goldman notes: "I have no general objection to individual epistemology [...] But given the deeply collaborative and interactive nature of knowledge seeking, especially in the modern world, individual epistemology needs a social counterpart: social epistemology" (Goldman 1999a, p. 4).
} 
It has already been hypothesized that testimonial isolation can causally contribute to the development of delusions. For example, Freeman and colleagues mention the lack of testimonial interaction in the etiology of the delusion of persecution: "[i]f the person is isolated, unable to revise his or her thoughts on the basis of interactions with supportive others, then ideas of threat are more likely to flourish. A similar process will occur if the person is reluctant to talk to others- he or she may be secretive or mistrustful, or believe that personal matters should not be discussed with others" (Freeman et al. 2002, pp. 355-356). ${ }^{10}$

What causes testimonial isolation in schizophrenia? It has been argued that possible causes include: social skill deficit (the lack of appropriate skills and competence in social and communicative exchanges; see Mueser et al. 1991) or social anhedonia (the reduced ability to experience pleasure from social relationships; see Blanchard et al. 2001). The former would deprive schizophrenic patients of the skills and competence necessary for testimonial interaction, while the latter would deprive them of the motivation for it.

Social cognition deficits might causally contribute to testimonial isolation as well. Various forms of social cognition deficits in schizophrenia have been reported (Penn et al. 2008), including emotion perception deficits (e.g., the failure to identify emotions displayed in facial expressions), Theory of Mind deficits (e.g., the failure to understand false beliefs, hints, intentions, deception, metaphor, irony, etc.), and attribution biases (e.g., the bias to blame others rather than situations for negative events).

Let us now turn to testimonial discount, which is perhaps more interesting than testimonial isolation from a philosophical point of view. Testimonial discount involves neglecting or discounting testimonial evidence.

We hypothesize that testimonial discount comes from the underestimation of competence and sincerity, which are among the crucial constituents of epistemic trustworthiness in testimony (Fricker 2007). ${ }^{11}$

Why do patients with schizophrenia underestimate testifier's competence and sincerity? A possibility is that paranoid thoughts or feelings, ${ }^{12}$ which are common in schizophrenia, cause patients to underestimate the sincerity of testifiers. If you think or feel that a person is trying to harm or harass you, then you probably will not think

\footnotetext{
10 Cameron expresses a similar idea (although his focus seems to be more on miscommunication than on the lack of testimonial interaction): "[t]he adult who is especially vulnerable to paranoid developments is one in whom this process of socialization has been seriously defective. His deficient social learning and poorly developed social skills leave him unable to understand adequately the motivations, attitudes, and intentions of others. When he becomes disturbed or confused under stress, he must operate under several grave handicaps imposed by a lifelong inability to communicate freely and effectively, to suspend judgment long enough to share his tentative interpretations with someone else, to imagine realistically the attitudes that others might have toward his situation and himself, and to imagine their roles and thus share their perspectives" (Cameron 1959, pp. 52-53).

11 There is a similarity between Fricker's (2007) account of testimonial injustice and our account of delusions. Fricker argues that testimonial injustice involves the underestimation of the competence and/or sincerity of the testifier who belongs to a stereotyped group and that the underestimation is caused by prejudices. Similarly, we argue that delusions involve the underestimation of the competence and sincerity of testifiers and that the underestimation is caused by social abnormalities in schizophrenia.

12 We speak of paranoid "thoughts or feelings" rather than paranoid "delusions", allowing for the possibility that such thoughts or feelings are not yet full-fledged delusions. See Sect. 4 for further discussion.
} 
of that person as a very sincere testifier. Perhaps the testifier has the malicious intent to deceive you as part of his strategy to harm or harass you.

Another possibility is that grandiose thoughts and feelings, which are also common in schizophrenia, cause patients to underestimate the competence of testifiers. When one thinks or feels one is special and has some special capacities (special cognitive capacities, in particular) that other people do not have, then one will probably be inclined to think that testifiers, in comparison to oneself, are not very competent, at least when it comes to certain topics.

The underestimation of competence and sincerity can undermine more than just testimony in a narrow sense, i.e., "a statement of someone's thoughts or beliefs, which they might direct to the world at large and to no one in particular" (Sosa 1991, p. 219). This is because the trustworthiness of evidence that is not testimonial in a narrow sense can be undermined by doubts about the competence and sincerity of some people involved in producing or transmitting the evidence.

For example, consider the case in which a doctor presents a delusional patient with a body of scientific data that strongly indicates the impossibility of the delusional hypothesis he adopts (e.g., "I have no internal organs"). The patient, who tends to underestimate competence and sincerity, might not trust the scientific evidence, thinking, for example, that the data were fabricated by the people trying to harm or harass him or that the relevant researchers are not as competent as he who, from his point of view, has special and privileged insight.

Another, particularly extreme, example is the "Truman syndrome". In this syndrome, which can be seen in the prodromal phase of schizophrenia, the patient has the impression that "the world ha[s] changed in some way that other people [a]re aware of, which he interpret[s] as indicating he [i]s the subject of a film and living in a film set (a 'fabricated world')" (Fusar-Poli et al. 2008). Here is a case reported by Fusar-Poli and colleagues:

Mr M.A., a 26-year-old postman, presented with the feeling there was something subtle going on around him that others knew about but he didn't. He had a vague sense that people around him were 'acting', he was the focus of their interest and they knew a secret that was being kept from him. Furthermore he felt 'detached from the environment' and had a sense the world was slightly unreal, as if he was the eponymous hero in the film The Truman Show. (Fusar-Poli et al. 2008, p. 168)

A patient with Truman syndrome feels that he has been the victim of a massive deception in a fabricated world, just as in the film The Truman Show. And, because of his feelings and thoughts about the massive deception, he might discount many, if not all, forms of evidence, including testimonial evidence.

\subsection{Group identification and testimonial discount}

We argued that testimonial discount can be caused by the underestimation of the competence and sincerity of testifiers. And such underestimation can, in turn, be caused by paranoid/grandiose/Truman thoughts and feelings. We now discuss another 
possible cause of the underestimation of competence and sincerity: the failure of group identification.

Our hypothesis is that the failure of group identification is a cause of the underestimation of competence and sincerity. Currently, direct evidence for this hypothesis is limited (mainly because research has only very recently begun to explore these issues). Still, we will now explain why our hypothesis has at least some degree of theoretical, empirical, and clinical plausibility. Our discussion is organized by the following questions about our hypothesis: (1) What is group identification; (2) How is group identification related to the estimation of competence and sincerity in testimonial exchanges; and (3) Why does group identification fail in schizophrenia?

1. What Is Group Identification? Social psychology (Brewer 1991; Turner 1982; etc.) and recent theories of collective intentionality (Pacherie 2013) converge on the idea that one motive for humans' ultra-cooperative nature (Tomasello 2019) is a particular self-understanding as agents. Often, when agents do things together in a collaborative way, they do so because they understand themselves as group members. Ever since the experiments on the so-called "minimal group paradigm" in the seventies (Tajfel et al. 1971), it has become customary to refer to the psychological process that leads to such self-understanding as "group identification."

Group identification has been the subject of extensive research for several decades. This branch of research shows that several conditions need to be fulfilled to acquire a self-conception as a group member. Some of these conditions can be described as follows. First, an individual is confronted with various "group cues" in the environment (Pacherie 2014). These cues include: having common interests, sharing a common fate, facing a competing group, using we-language, etc. (Bacharach 2006). If the individual becomes aware of these cues, i.e., if these cues become salient to the individual, then that awareness can trigger two interrelated consequences: self-categorization and depersonalization (because the term "depersonalization" also denotes a psychiatric symptom and a disorder (American Psychiatric Association 2013, p. 302ff.), we shall replace it with the term "de-individuation").

When subjects self-categorize, they begin to see themselves as saliently similar to others (those who, e.g., have the same preferences, exemplify the same properties, happen to share the same conditions of life, etc.). Self-categorization is correlated with de-individuation insofar as categorizing oneself as similar to another is conducive to de-emphasizing one's idiosyncratic traits as an individual in favor of stereotypical self-perception. Depersonalization (in the socio-psychological sense at stake here) has thus been described as "a shift towards the perception of self as an interchangeable exemplar of some social category and away from the perception of self as a unique person defined by individual differences from others" (Turner 1982, p. 50).

The endpoint of group identification is the formation of self-understanding as a group member, which has also been characterized as a "social self" (Brewer 1991, Salice and Miyazono 2019). The social self enables an individual to share collective or we-intentions and, thereby, to engage in collaborative endeavors (or to interact in "the we-mode" as it is sometimes put; see Tuomela 2007).

2. How Is Group Identification Related to the Estimation of Competence and Sincerity? It is plausible to theorize that, once one group-identifies, one regards other 
group members as more cooperative and sincere in group activities, including testimonial exchanges, than non-group members. For example, in the classic experiment by Tajfel (1970; Tajfel et al. 1971), the participant, who understands himself as a Kandinsky lover, might regard other Kandinsky lovers as more cooperative and sincere in group activities, including testimonial exchanges, than Klee lovers. This phenomenon is called "depersonalized trust" in the literature (Brewer 1990), and it refers to a form of trust (understood as an expectation of cooperation) that is "extended to any member of the ingroup whether personally related or not" (Brewer 1999, p. 433).

More speculatively, it could be suggested that, once one group-identifies, one regards other group members as more competent in some activities, possibly including testimonial exchanges, than non-members. When one understands oneself as a Kandinsky lover, one might regard other Kandinsky lovers as more competent in testimonial exchanges, at least on some particular topics such as aesthetic topics, than Klee lovers. This can be understood as a group-based version of the self-serving bias.

The upshot of these considerations is that, when one group-identifies with testifiers, one tends to regard them as sincere and competent. Our hypothesis is that this process is compromised in schizophrenia, i.e., schizophrenic patients tend to fail to groupidentify and, because of that, they are not inclined to regard testifiers as sincere and competent. A normal individual, for example, identifies himself as a Kandinsky lover, which causes him to regard other Kandinsky lovers as sincere and competent. A schizophrenic patient, by contrast, fails to identify as a member of any particular group and, thus, does not regard testifiers as sincere and competent.

3. Why Does Group Identification Fail in Schizophrenia? ${ }^{13}$ It has been argued that some of the factors that render group identification fragile in schizophrenia are non-psychotic, anomalous self-experiences which are at the core of the psychopathology of schizophrenia (Sass 2014; Sass and Parnas 2003). Contemporary research demonstrates that these "ipseity disturbances" or "self-disorders" hyperaggregate in schizophrenia, but not in other mental disorders (see Parnas and Henriksen 2014). Therefore, they can be considered as trait-like features of the disorder, which precede psychosis and persist after remission.

Of the approx. twenty anomalous self-experiences identified by current research, four are particularly relevant to the fragility of group identification (Salice \& Henriksen 2015). More specifically, group identification is destabilized by (i) ontological dissimilarity and (ii) common sense problems; de-individuation is hampered by (iii) experiences of hyper-reflection and (iv) transitivism. The remainder of this section briefly elaborates on these self-disorders and on their impact on group identification.

(i) By "ontological dissimilarity" we mean profound, basic, and pervasive feelings of being different from others. For instance, one patient reports: "I looked just like every other child, but inside I was different. It is as if I am another creature

\footnotetext{
13 This subsection substantially draws on the collaborative work between A. Salice and M.G. Henriksen presented in Salice and Henriksen (2015) and Salice and Henriksen (under review). In these works, the interested readers can find further details on the relations between anomalous self-experiences, group identification, and shared intentionality in schizophrenia.
} 
that somehow ended up inside a human body" (Henriksen and Nordgaard 2014). Ontological dissimilarity may impede the recognition of concrete similarities (such as sharing the same taste in music, having the same skin color, supporting the same football team, etc.) and/or present such similarities as superficial, insignificant or arbitrary. Thus, it can be surmised that ontological dissimilarity impairs self-categorization insofar as it hinders the perception of oneself as similar to other individuals.

(ii) Ontological dissimilarity correlates with the loss of common sense (Blankenburg 1971; Stanghellini 2004). This experience has been claimed to consist in a lack of both basic attunement to the world and a pre-reflective understanding of the meaning of everyday social interactions, situations, and objects. It usually manifests itself as an inability to take for granted what other individuals consider obvious, self-evident, or even trivial (often reflected in questions like "why do people say 'hello' to each other?" or "why is the sky blue?" Parnas and Henriksen 2014). Because of these features, loss of common sense might be argued to hamper the perception of salient group cues: the recognition of group cues is made difficult by the lack of common sense, which exerts friction on the process of self-categorization.

(iii) Hyper-reflectivity is the tendency to place oneself- or aspects of the environment-at the center of intense reflection (Sass 1992). Especially when it takes the first form, hyper-reflexivity consists in excessive self-monitoring, which accompanies the patient's interactions with others and hinders his spontaneous immersion in the shared social world (by depriving the patient of energy or motivation). This constant self-monitoring makes it difficult for the patient to lose sight of his/her personal and unique traits, thereby counteracting the process of de-individuation (which has been described as stereotypical self-perception in terms of properties shared with other group members).

(iv) Transitivism refers to experiences of permeable self-other or self-world boundaries (also called "demarcation problems"). At the core of these phenomena is a transient experience of permeability or the blurring of the boundaries that separate oneself from others and the world (e.g., experiences of being "mixed up" with another person and of being unable to tell which thoughts or feelings originate in whom). We conjecture that transitivistic experiences counter deindividuation: because of the profoundly disturbing nature of these experiences, it appears plausible that patients with schizophrenia would tend to avoid any circumstances that have the capacity to blur their identity (including those that facilitate the acquisition of stereotypical self-perception).

\section{Objections}

We now turn to three expected objections to the testimonial theory of delusions.

Objection 1 The testimonial theory of delusions is causally and explanatorily circular. Perhaps it is true that patients with paranoid/grandiose/Truman delusions tend not to trust testimony from others. But this is an effect, not a cause, of the delusions. 
What is the cause of the paranoid/grandiose/Truman delusions? Are they caused by testimonial discount, too? If so, what is the cause of such testimonial discount? Paranoid/grandiose/Truman delusions?

In response, we first point out that we did not claim that paranoid/grandiose/Truman delusions cause testimonial discount. Rather, we claimed that paranoid/grandiose/Truman thoughts and feelings cause testimonial discount, allowing for the possibility that the "thoughts and feelings" are not yet full-fledged delusions. For example, one can constantly feel that one has been harassed by co-workers without yet seriously believing it. Or one can think (in the sense of entertaining a proposition) that one has a special power to predict future events without yet seriously believing it. And these thoughts and feelings might cause testimonial discount. The same is true for the Truman syndrome, which is already present in the prodromal stage before the onset of positive symptoms such as (full-fledged) delusions (Fusar-Poli et al. 2008). (And it is possible that paranoid/grandiose/Truman thoughts and feelings are related to anomalous self-experiences that we mentioned in Sect. 3.3.)

Perhaps the whole process can be formulated as follows. Paranoid/grandiose/Truman thoughts and feelings cause testimonial discount, which in turn causes some full-fledged delusions. These delusions can be (but do not have to be) paranoid/grandiose/Truman delusions, in which case they might strengthen testimonial discount. This causal chain might lead to a cyclical process in which paranoid/grandiose/Truman delusions and testimonial discount strengthen each other. But this process is not viciously circular.

Secondly, we stress again the distinction between the adoption, maintenance, and elaboration/polythematization stages. As we already noted, we are inclined to think that testimonial abnormalities are not the main factor in the adoption stage. The role, if any, of testimonial abnormalities is minimal in the adoption stage. Still, the following story, which is not circular and is in line with the testimonial theory, presents itself. First, paranoid/grandiose/Truman delusions are adopted in response to some causes that are not testimonial abnormalities. And, then, once adopted, the delusions cause testimonial discount, which in turn causes the paranoid/grandiose/Truman delusions to be maintained despite obvious counterevidence and to be elaborated into an intricate delusional belief system.

Objection 2 The testimonial theory is not able to deal with folie à deux, or shared psychosis, in which a delusion is shared by multiple individuals. Radden (2010), for example, discusses a case of shared delusional parasitosis in which a mother persuaded her son that they were both infected with parasites. This case does not seem to involve any testimonial abnormalities. In fact, this seems to be a case of normal and reasonable testimony in which one person (the mother) successfully informs another (the son). As Radden notes, "[i]n light of the ways of normal (and normative) social learning, particularly among intimates, the inducing of an idea in one person by another in folie à deux seems likely to conform to epistemic norms governing the acquisition of those states: their mode of transfer will be unexceptional" (Radden 2010, p. 81).

A possible response to this challenge would be to deny the idea that the belief of the second party (i.e., the son in the above case) is a delusion. So, for example, the 
son's belief about infection does not count as a delusion. Since it is not a delusion, it does not count as a counterexample to our claim that delusions involve testimonial abnormalities. This, however, is not our favorite response because it is difficult to see a principled reason (i.e., the one that goes beyond mere stipulation) to deny the possibility that the beliefs of the second party are genuinely delusional, indistinguishable from what we take to be genuine delusions.

Another response, which is more promising, would be to deny the assumption that testimonial processes are entirely normal in folie à deux. As we already noted, the development of delusions is a complex process with different stages. Even if the son acquires the delusion through a normal testimonial process at the adoption stage, this does not rule out the possibility that some testimonial abnormalities are involved in other stages. In other words, folie à deux might involve testimonial abnormalities somewhere other than in the adoption stage. ${ }^{14}$

Furthermore, folie à deux might involve a different kind of testimonial abnormality. A tempting idea would be that folie à deux involves testimonial isolation and/or testimonial discount at a collective level. For example, it can be conjectured that, insofar as the son and the mother form a group (and a particularly cohesive one) and insofar as groups can engage in testimonial interactions (Tollefsen 2007), as a group, they fail to engage in such interactions with non-members (a phenomenon that might be called "collective testimonial isolation"). Or, as a group, the son and the mother discount testimonial evidence from non-members ("collective testimonial discount"). ${ }^{15}$

Alternatively, folie à deux might involve the overrating (rather than discounting) of testimonial evidence from some particular individuals (e.g., the mother). Such abnormal overrating might be caused by the overestimation (rather than underestimation) of the competence and sincerity of the particular individuals, which in turn might be due to excessive (rather than fragile) group identification with the individuals. The idea of excessive group identification in folie à deux is coherent with the observation that folie à deux is often seen in families and that families are characterized by particularly intense group identification among their members (which is illustrated by the effect that family identification has on family members' psychological well-being; see Sani 2012).

Objection 3 The testimonial theory overgeneralizes, in the sense that it falsely predicts that patients have delusions about too many issues and topics. Earlier we quoted from Goldman's statement that "[m]ost of what we believe is influenced, directly or indirectly, by utterances and writings of others" (Goldman 1999b, p. 3). If Goldman is correct about this, then we would expect those with testimonial abnormalities to become delusional about most of what they believe. But this does not seem to be the case. Delusional patients have many non-delusional testimonial beliefs.

We have two answers to this challenge. First, it is not obvious that the testimonial theory overgeneralizes because delusional patients do have delusions about many

\footnotetext{
14 Langdon (2013) and Radden (2010) also suggest that the abnormalities in folie à deux are located in the maintenance stage, not in the adoption stage.

15 Although nothing about our suggested explanation hinges on this, the hypothesis that groups can have psychiatric disorders has already attracted some attention (see Hoffman 2019).
} 
issues and topics in schizophrenia where delusions tend to be elaborated and polythematic. Schizophrenic patients can be delusional about multiple issues and topics, and they can form a system of delusional beliefs. Thus, it could be a theoretical advantage, rather than a disadvantage, that the testimonial theory predicts that patients have delusions about many issues and topics.

However, a worry still remains: perhaps the testimonial theory predicts that delusional patients have more delusions (about more topics and issues) than they actually have, even in polythematic and elaborated cases. Delusional patients have many nondelusional testimonial beliefs, even in polythematic and elaborated cases. For example, in response to the testimony of a nurse, a patient might form the non-delusional belief that the clinic will be closed next Wednesday. How can this be possible if the patient has testimonial abnormalities?

This leads us to our second answer. The testimonial theory does not rule out the possibility that patients have many non-delusional testimonial beliefs. As we already noted, we are committed to a multifactorial approach; testimonial abnormalities are not meant to be sufficient for a patient to be delusional. Other factors (such as experiential abnormalities) are also necessary. In particular, we suggested above that the adoption stage is mainly due to experiential factors. Testimonial factors are mainly responsible for the maintenance stage and the elaboration/polythematization stage. Thus, the reason why a patient does not adopt a delusional hypothesis about the clinic's schedule next week is because the relevant abnormal experience (a hallucinatory voice saying that "the nurse is telling a lie about the clinic's schedule") is lacking.

However, once the patient actually has such an abnormal experience, then we do predict that a delusional hypothesis about the clinic is adopted in response to the abnormal experience, maintained despite counterevidence, and possibly elaborated and polythematized.

\section{Conclusions}

This paper advocates a social epistemological turn in the study of delusions. It is a turn from the (purely) individualistic conception, which characterizes delusions in terms of individualistic sources of evidence alone, to the (partially) social epistemic conception, which characterizes delusions in terms of individual as well as social sources of evidence.

As an initial step toward such a turn, we proposed the testimonial theory of delusions according to which testimonial abnormalities, such as testimonial isolation and testimonial discount, constitute a causal factor in the development of delusions. Testimonial abnormalities might not explain everything about the development of delusions (which is why, strictly speaking, the testimonial theory is a "partial" theory of delusions), but they can be argued to be an important piece in the puzzle of the etiology of delusions.

Acknowledgements Early versions of this paper were presented at International Workshop on Philosophy of Psychiatry (December 2, 2018, at University of Tokyo) and The 3rd Cork Annual Workshop on Social Agency (August 27, 2018, at University College Cork). We thank Mads G. Henriksen for helpful discussions 
on delusions in schizophrenia. We acknowledge the support of the Suntory Foundation (2016, 2017), and Kengo Miyazono acknowledges the support of JSPS KAKENHI (Grant No. 18H00605).

Open Access This article is licensed under a Creative Commons Attribution 4.0 International License, which permits use, sharing, adaptation, distribution and reproduction in any medium or format, as long as you give appropriate credit to the original author(s) and the source, provide a link to the Creative Commons licence, and indicate if changes were made. The images or other third party material in this article are included in the article's Creative Commons licence, unless indicated otherwise in a credit line to the material. If material is not included in the article's Creative Commons licence and your intended use is not permitted by statutory regulation or exceeds the permitted use, you will need to obtain permission directly from the copyright holder. To view a copy of this licence, visit http://creativecommons.org/licenses/by/4.0/.

\section{References}

American Psychiatric Association. (2013). Diagnostic and statistical manual of mental disorders (5th ed.). Cambridge: American Psychiatric Publishing.

Bacharach, M. (2006). Beyond individual choice: Teams and frames in game theory. Princeton: Princeton University Press.

Blanchard, J. L., Horan, W. P., \& Brown, S. A. (2001). Diagnostic differences in social anhedonia: A longitudinal study of schizophrenia and major depressive disorder. Journal of Abnormal Psychology, $110(3), 363$.

Blankenburg, W. (1971). Der Verlust der natürlichen Selbstverständlichkeit. Ein Beitrag zur Psychopathologie symptomarmer Schizophrenien: Enke.

Bortolotti, L. (2010). Delusions and other irrational beliefs. Oxford: Oxford University Press.

Bortolotti, L. (2013). Rationality and sanity: The role of rationality judgements in understanding psychiatric disorders. In K. W. M. Fulford, M. Davies, R. Gipps, G. Graham, J. Sadler, G. Stanghellini, \& T. Thornton (Eds.), The Oxford handbook of philosophy and psychiatry (pp. 480-496). Oxford: Oxford University Press.

Brewer, M. B. (1991). The social self: On being the same and different at the same time. Personality and Social Psychology Bulletin, 17(5), 475-482.

Brewer, M. B. (1999). The psychology of prejudice: Ingroup love or outgroup hate? Journal of Social Issues, 55(3), 429-444.

Broome, M. R., \& Bortolotti, L. (2009). Mental illness as mental: In defence of psychological realism. Humana Mente, 11, 25-43.

Cameron, N. (1959). The paranoid pseudo-community revisited. American Journal of Sociology, 65(1), 52-58.

Coltheart, M. (2007). The 33rd Sir Frederick Bartlett lecture cognitive neuropsychiatry and delusional belief. The Quarterly Journal of Experimental Psychology, 60(8), 1041-1062.

Coltheart, M. (2013). On the distinction between monothematic and polythematic delusions. Mind and Language, 28(1), 103-112.

Coltheart, M., Langdon, R., \& McKay, R. (2011). Delusional belief. Annual Review of Psychology, 62, 271-298.

Coltheart, M., Menzies, P., \& Sutton, J. (2010). Abductive inference and delusional belief. Cognitive Neuropsychiatry, 15(1-3), 261-287.

Corlett, P. R., Murray, G. K., Honey, G. D., Aitken, M. R., Shanks, D. R., Robbins, T. W., et al. (2007). Disrupted prediction-error signal in psychosis: Evidence for an associative account of delusions. Brain, 130(9), 2387-2400.

Corlett, P. R., Taylor, J. R., Wang, X. J., Fletcher, P. C., \& Krystal, J. H. (2010). Toward a neurobiology of delusions. Progress in Neurobiology, 92(3), 345-369.

Davies, M., Coltheart, M., Langdon, R., \& Breen, N. (2001). Monothematic delusions: Towards a two-factor account. Philosophy, Psychiatry, \& Psychology, 8(2), 133-158.

Ellis, H. D., Young, A. W., Quayle, A. H., \& De Pauw, K. W. (1997). Reduced autonomic responses to faces in Capgras delusion. Proceedings of the Royal Society of London. Series B: Biological Sciences, 264(1384), 1085-1092. 
Fletcher, P. C., \& Frith, C. D. (2009). Perceiving is believing: A Bayesian approach to explaining the positive symptoms of schizophrenia. Nature Reviews Neuroscience, 10(1), 48-58.

Freeman, D., Garety, P. A., Kuipers, E., Fowler, D., \& Bebbington, P. E. (2002). A cognitive model of persecutory delusions. British Journal of Clinical Psychology, 41(4), 331-347.

Fricker, M. (2007). Epistemic injustice: Power and the ethics of knowing. Oxford: Oxford University Press.

Fuchs, T. (2015). The intersubjectivity of delusions. World Psychiatry, 14(2), 178.

Fusar-Poli, P., Howes, O., Valmaggia, L., \& McGuire, P. (2008). 'Truman' signs and vulnerability to psychosis. The British Journal of Psychiatry, 193(2), 168-168.

Garety, P. A., \& Hemsley, D. R. (1997). Delusions: Investigations into the psychology of delusional reasoning. London: Psychology Press.

Garety, P. A., Kuipers, E., Fowler, D., Freeman, D., \& Bebbington, P. E. (2001). A cognitive model of the positive symptoms of psychosis. Psychological Medicine, 31(2), 189-195.

Goldman, A. I. (1999a). Knowledge in a social world. Oxford: Oxford University Press.

Goldman, A. I. (1999b). Social epistemology. Crítica Revista Hispanoamericana de Filosofía, 31(93), 3-19.

Goldman, A. I. (2011). A guide to social epistemology. In A. I. Goldman \& D. Whitcomb (Eds.), Social epistemology: Essential readings (pp. 11-37). Oxford: Oxford University Press.

Goldman, A. I. \& O’Connor, C. (2019). Social epistemology. In Zalta, E. N. (ed.), The stanford encyclopedia of philosophy (Fall 2019 Edition). https://plato.stanford.edu/archives/fall2019/entries/epistemologysocial/.

Henriksen, M. G., \& Nordgaard, J. (2014). Schizophrenia as a disorder of the self. Journal of Psychopathology, 20, 435-441.

Hoffman, G. A. (2019). Collectively ill: A preliminary case that groups can have psychiatric disorders. Synthese, 196(6), 2217-2241.

Huq, S. F., Garety, P. A., \& Hemsley, D. R. (1988). Probabilistic judgements in deluded and non-deluded subjects. The Quarterly Journal of Experimental Psychology, 40(4), 801-812.

Jaspers, K. (1963). General psychopathology. Manchester: Manchester University Press.

Kapur, S. (2003). Psychosis as a state of aberrant salience: A framework linking biology, phenomenology, and pharmacology in schizophrenia. American Journal of Psychiatry, 160(1), 13-23.

Langdon, R. (2013). Folie à deux and its lessons for two-factor theorists. Mind and Language, 28(1), 72-82.

Maher, B. A. (1974). Delusional thinking and perceptual disorder. Journal of Individual Psychology, 30(1), 98.

Miyazono, K., \& McKay, R. (2019). Explaining delusional beliefs: A hybrid model. Cognitive Neuropsychiatry, 24(5), 335-346.

Moritz, S., \& Woodward, T. S. (2006). A generalized bias against disconfirmatory evidence in schizophrenia. Psychiatry Research, 142(2-3), 157-165.

Mueser, K. T., Bellack, A. S., Douglas, M. S., \& Morrison, R. L. (1991). Prevalence and stability of social skill deficits in schizophrenia. Schizophrenia Research, 5(2), 167-176.

Murphy, D. (2013). Delusions, modernist epistemology and irrational belief. Mind and Language, 28(1), $113-124$.

Pacherie, E. (2013). Intentional joint agency: Shared intention lite. Synthese, 190(10), 1817-1839.

Parnas, J., \& Henriksen, M. G. (2014). Disordered self in the schizophrenia spectrum: A clinical and research perspective. Harvard Review of Psychiatry, 22(5), 251-265.

Penn, D. L., Sanna, L. J., \& Roberts, D. L. (2008). Social cognition in schizophrenia: An overview. Schizophrenia Bulletin, 34(3), 408-411.

Radden, J. (2010). On delusion. London: Routledge.

Ross, R. M., \& McKay, R. (2017). Why is belief in God not a delusion? Religion, Brain \& Behavior, 7(4), 316-319.

Salice, A., \& Henriksen, M. G. (2015). The disrupted 'we': Schizophrenia and collective intentionality. Journal of Consciousness Studies, 22(7-8), 145-171.

Salice, A., \& Henriksen, M. G. (under review). Disturbances of shared intentionality in schizophrenia and autism.

Salice, A., \& Miyazono, K. (2019). Being one of us. Group identification, joint actions, and collective intentionality. Philosophical Psychology, 33, 42-63.

Sani, F. (2012). Group identification, social relationships, and health. In J. Jetten, C. Haslam, \& S. A. Haslam (Eds.), The social cure: Identity, health and well-being (pp. 21-37). London: Psychology Press.

Sass, L. A. (1992). Madness and modernism: Insanity in the light of modern art, literature, and thought. Harvard: Harvard University Press. 
Sass, L. A., \& Parnas, J. (2003). Schizophrenia, consciousness, and the self. Schizophrenia Bulletin, 29(3), 427-444.

Sosa, E. (1991). Knowledge in perspective: Selected essays in epistemology. Cambridge: Cambridge University Press.

Stanghellini, G. (2004). Disembodied spirits and deanimated bodies: The psychopathology of common sense. Oxford: Oxford University Press.

Stone, T., \& Young, A. W. (1997). Delusions and brain injury: The philosophy and psychology of belief. Mind and Language, 12(3-4), 327-364.

Tajfel, H. (1970). Experiments in intergroup discrimination. Scientific American, 223(5), 96-103.

Tajfel, H., Billig, M. G., Bundy, R. P., \& Flament, C. (1971). Social categorization and intergroup behaviour. European Journal of Social Psychology, 1(2), 149-178.

Tollefsen, D. (2007). Group Testimony. Social Epistemology, 21(3), 299-311.

Tomasello, M. (2019). The moral psychology of obligation. Behavioral and Brain Sciences. https://doi.org/ 10.1017/S0140525X19001742.

Tuomela, R. (2007). The philosophy of sociality: The shared point of view. Oxford: Oxford University Press.

Turner, J. C. (1982). Towards a cognitive redefinition of the social group. In H. Tajfel (Ed.), Social identity and intergroup relations (pp. 15-40). Cambridge: Cambridge University Press.

Von Domarus, E. (1944). The specific laws of logic in schizophrenia. In J. S. Kasanin (Ed.), Language and thought in schizophrenia (pp. 104-114). California: University of California Press.

Woodward, T. S., Moritz, S., Cuttler, C., \& Whitman, J. C. (2006). The contribution of a cognitive bias against disconfirmatory evidence (BADE) to delusions in schizophrenia. Journal of Clinical and Experimental Neuropsychology, 28(4), 605-617.

Publisher's Note Springer Nature remains neutral with regard to jurisdictional claims in published maps and institutional affiliations. 